\title{
Cinderela de sapatinho quebrado: maternidade, não maternidade e maternagem nas histórias contadas pelas mulheres
}

\author{
Cinderella's shoe broken: maternity, no maternity, and parenting in \\ stories told by women
}

Jacqueline Simone de Almeida Machado', Cláudia Maria de Mattos Penna², Regina Célia Lima Caleiro 3

DOI: 10.1590/0103-1104201912311

RESUMO Estudo qualitativo, alicerçado na história oral, realizado com 19 mulheres, com o objetivo de analisar narrativas de mulheres sem filhos em relação à maternidade e à não maternidade. A análise das narrativas aponta que as mulheres vivenciaram historicamente mudanças nos valores e práticas que resultaram em novas concepções acerca da identidade feminina, impactando o ideal feminino de mulher-mãe, presente no imaginário social. A maternidade, que foi socialmente construída, assume novo valor na contemporaneidade, e ter ou não filho resulta do desejo de cada mulher.

PALAVRAS-CHAVE Comportamento materno. Mulheres. Identidade de gênero.

\begin{abstract}
Qualitative study, based on Oral History, conducted with nineteen women, with the purpose of analyzing narratives of women without children in relation to motherhood and not motherhood. The analysis of the narratives points out that women have historically experienced changes in values and practices that have resulted in new conceptions regarding female identity, impacting the feminine ideal of the womanmother, present in the social imaginary. Motherhood, which was socially constructed, takes on a new value in contemporary times and the decision to whether or not have a child results from the desire of every woman.
\end{abstract}

KEYWORDS Maternal behavior. Women. Gender identity.

\footnotetext{
1 Universidade Federal de São João Del Rei (UFSJ) - São João Del Rei (MG), Brasil.

jack.machado@hotmail.com

2 Universidade Federal de Minas Gerais (UFMG)

- Belo Horizonte (MG),

Brasil.

3 Universidade Estadual de Minas Gerais (Unimontes) - Montes Claros (MG)

Brasil.
} 


\section{Introdução}

\section{Mãe doce mãe, lar doce lar ou os efeitos do biopoder}

Se a função maternal, até o século XVII, não era valorizada socialmente, podemos afirmar que, no final do século XVIII, houve uma mudança extremamente significativa. Reconhecida e incentivada, tornou-se alvo das mais diversas recomendações quanto aos cuidados que as mães deveriam dedicar aos filhos' 1 . No despontar do século XIX, ao rol dos valores burgueses, foram inseridas a devoção ao lar e a presença vigilante e amorosa da mãe que transformaram a nova mulher em 'rainha do lar'2.

O culto à maternidade e de todas as funções exigidas pela manutenção do bem-estar da prole foi o terreno fértil para que o amor materno fosse naturalizado e generalizado enquanto condição feminina referendada pelo determinismo biológico ${ }^{3}$. A partir de então, prevaleceu socialmente a "ideia de maternidade como elemento definidor da condição de feminilidade"4(105).

Na virada do século XX, particularmente no Brasil, a maternidade atestava a importância das mulheres brancas na vida privada; e os discursos sobre a sua natureza contribuíram para segregá-las ao lar e impedir que seus direitos civis, econômicos, políticos, sociais e intelectuais fossem exercidos plenamente. Nesse contexto, a maternidade proporcionava reconhecimento social; e até a década de 1970, era um processo natural dentro do casamento, em que a reprodução representava instinto natural aliado ao dever de perpetuar a espécie ${ }^{5}$.

No contexto histórico no qual foi elaborado o ideal de mulher-mãe, a maternidade era condição sine qua non para que a mulher estruturasse sua identidade feminina e se reconhecesse como 'normal'.

Ao tratar das mulheres que fugiram do comportamento 'natural', Dias fez referência ao erro dessas abordagens generalizantes que trataram a 'mulher' como uma categoria universal com características comuns determinadas organicamente, constituindo, aquelas de comportamento diverso, versões anormais. Tal postura revela-se ilusória, pois a 'mulher universal' e o 'homem universal' são criações mentais inexistentes no campo factual6(113).

Contudo, deve-se que considerar que as identidades são construções discursivas e culturais, e não fixas ou imutáveis. A identidade de gênero também é construída historicamente, e os discursos constituem o sujeito, em uma versão foucaultiana em que este sujeito é o efeito das relações entre saber e poder. O sujeito é constituído, é fundado nas relações que se organizam em torno dele, e pode-se falar, portanto, em uma construção cotidiana do feminino ${ }^{7}$.

No Brasil, entre o final do século XIX e o início do século XX, o projeto de higienização que se ocupou dos corpos das mulheres e a construção do modelo mulher-mãe objetivavam moldar o comportamento feminino por intermédio do casamento indissolúvel, comedido, recatado, em que a sexualidade tinha como objetivo a procriação. A intervenção médico-estatal sobre a sociedade incidiu primordialmente no comportamento familiar e delegou lugares específicos para homens e mulheres. No casamento concebido como ideal, a escolha dos cônjuges estava atrelada à saúde da prole que não dependia unicamente dos cuidados ministrados após o seu nascimento, mas da condição física e moral dos pais antes e após o contrato conjugal. Os valores patriarcais foram suprimidos ou reprimidos; e, em troca, foram concedidos aos indivíduos direitos à sexualidade e à afetividade. Essa nova forma de aburguesamento da sociedade oitocentista, e também da sociedade republicana, foi possível graças ao novo enfoque dado ao amor que permitiu ao projeto higienista

realizar sua manobra mais ambiciosa e, talvez, mais bem-sucedida junto à família: converter quase completamente a figura sentimental do homem ao personagem do pai, e a da mulher ao personagem da mãe $\mathbf{8}^{\mathbf{2 ( 2 9 3 )}}$. 
Diante do exposto, afirma-se que a maternidade é um fato social e, portanto, socialmente produzida e significada, o que provocou a reflexão de muitos autores que se debruçaram sobre o tema.

Com esses pressupostos, sugere-se pensar a maternidade como uma questão biopolítica visto que ainda persiste a vinculação da mulher à maternidade, pois

a centralidade na mulher-mãe reforça estereótipos sobre a condição feminina dentro de um viés biologicista que coloca como predisposições naturais a função de boa cuidadora no âmbito privado/doméstico9(161).

Foucault apresenta a definição de biopolítica como a intervenção e a vigilância exercida sobre os corpos, ou seja, é uma tecnologia disciplinar iniciada nos séculos XVII e XVIII pelas técnicas de poder centradas no corpo para aumentar sua capacidade. Ele propõe outra visão das instâncias sociais, mediante um novo conceito de poder, ou seja, a modernidade apresenta novas estratégias de poder, de verdade e de subjetividade ${ }^{10-12}$. Destarte, o corpo feminino é atrelado à maternidade, garantindo à mulher uma identidade, qual seja, a mãe.

As biopolíticas estudadas por Foucault estavam a serviço da formação dos Estados Nacionais e das classes burguesas e propunham novos valores. A biopolítica enfatizava a sexualidade, produzindo identidades via desejo sexual, ligado

à produção de corpos dóceis, submissos e disciplinados, à consistência ontológica da subjetividade e ao universalismo ético que possibilitava a implantação de uma identidade nas práticas subjetivantes modernas ${ }^{10(11)}$.

Ao implementar políticas de natalidade, saúde, higiene etc., a biopolítica revela as formas de assujeitamento dos indivíduos. Tomados enquanto conjunto, são incluídos no sistema normalizador, e o poder exercido sobre os corpos vai domesticá-los, tornando-os submissos e eficazes. As práticas subjetivantes derivam, portanto, das tecnologias políticas utilizadas na fabricação do sujeito 11,12.

Foucault, na 'História da Sexualidade III', revela a valorização da sexualidade pela medicina a partir do século XIX, assegurando o controle do organismo e do desejo. Se o poder constitui a realidade e é composto por tecnologias que incidem sobre o corpo, este passa a ser moldado para atender aos interesses do primeiro. Assim, a sexualidade é vista como um dispositivo de dominação do corpo e do desejo.

Entretanto, há que se considerar que as mudanças ocorridas no século XX, como os movimentos sociais, lutas políticas, o feminismo e o surgimento da pílula anticoncepcional, impulsionaram a possibilidade de outras escolhas e a desnaturalização da maternidade como condição feminina da mulher ${ }^{13}$.

A identidade feminina é resultado dos processos históricos, pelas vivências singulares e coletivas, cotidianamente, marcada pelos discursos e valores sociais. Segundo Maffesoli ${ }^{14}$, para compreender esse processo de construção, é preciso perceber os valores compartilhados cotidianamente.

A construção do feminino faz-se nas instâncias do social, passando pela representação dos corpos, da sexualidade e das relações de gênero, nas quais as relações de poder, no sentido foucaultiano, produzem normas que influenciam ou pretendem determinar a condição feminina. Essa construção se dá pelos processos de subjetivação que acontecem cotidianamente.

Para Maffesoli ${ }^{\mathbf{1 4}}$, esse cotidiano é definido pela maneira de viver de cada pessoa e do coletivo, o saber-fazer, o saber-dizer e o saber-viver. A vida não se reduz ao sujeito individual, mas ressurge na socialidade, denominada por ele como uma espécie de empatia comunalizada, ou seja, é a experiência coletiva que acontece no dia a dia, é o conhecimento comum que alicerça essa construção. $\mathrm{O}$ autor nos convida a compreender a existência feminina por meio dos aspectos cotidianos, das ações subjetivas dos sujeitos nos seus ambientes de vivência coletiva, pois a experiência comum é parte 
fundamental da trama societal. Em sua análise social, valoriza os aspectos do sentimento e do imaginário, e o imaginário individual corresponde ao imaginário do grupo no qual o indivíduo se encontra inserido. A vida social é feita de emoções, sentimentos e afetos compartilhados, em que a subjetividade tanto se ancora como interioriza os valores coletivos.

Se a ideia de que a realização da mulher pela maternidade está sendo desconstruída e que na atualidade ela conquista espaço para fazer suas escolhas, isso resulta em uma mudança social e na ruptura com o papel feminino unívoco. Historicamente, todo o processo de mudança possibilitou alterações nas formas de construção de identidade e subjetivação, fazendo surgir novos papéis e formas de manifestações femininas ${ }^{13,15,16}$.

O percurso histórico do movimento feminista abriu o caminho das pesquisas acadêmicas com ambições mais teóricas que em seu conjunto pretendia

criticar os saberes constituídos, que se davam como universais a despeito do seu caráter predominantemente masculino [...] assim nasceu o desejo de um outro relato, de uma outra história17(20).

Segundo Gonçalves ${ }^{18}$, as abordagens feministas possibilitaram considerar outras facetas simbólicas da maternidade, considerada não como dado biológico, mas socialmente construída.

Perceber o cotidiano da cultura e sua produção de sentidos torna-se necessário para compreender a forma como o sujeito percebe, interpreta o mundo e o experiencia, visto que a razão não é suficiente para explicar a complexidade da vida cotidiana ou dos modos de relação entre sujeito e mundo.

\section{Métodos}

Este estudo está alicerçado na história oral e apresenta uma pesquisa qualitativa que faz uso de fontes orais, coletadas por entrevistas para revelar as experiências dos sujeitos envolvidos. Seus registros são importantes para consideração social, pois a história oral deixa de ser documento equiparável aos preexistentes, escritos, fundamentando nova versão dos fatos. $\mathrm{O}$ método de história oral é um processo dinâmico que envolve a utilização de narrativas transformadas da forma oral para a escrita, norteando processos sociais ao favorecer investigações no âmbito da memória cultural e individual. Nessa ótica de trabalho, o tipo de história oral a ser utilizada será a híbrida, quando as narrativas se mesclam com a literatura, a partir de uma análise cruzada. Toma a história oral temática como gênero narrativo, revelando o que as colaboradoras pensam sobre identidade feminina, não maternidade e a maternagem exercida por mulheres sem filhos ${ }^{19}$.

Fundamenta-se na sociologia compreensiva do cotidiano de Michel Maffesoli, que parte da experiência subjetiva do sujeito uma vez que ele se constrói, em determinado tempo e espaço, permitindo uma compreensão da história narrada por cada mulher, considerando todo o seu contexto e respeitando a visão subjetiva dos fatos; e no conceito de biopolítica de Michel Foucault, que regulamenta e faz a gestão da vida pelos mecanismos e tecnologias aplicadas à população, normatizando e regulando o corpo feminino, construindo um discurso científico sobre condição feminina e maternidade.

A pesquisa envolveu 19 mulheres de diferentes idades, profissões, estrato socioeconômico, estado civil e orientação sexual, brancas e não brancas, oriundas de cidades de pequeno e médio porte, assim como de capitais, escolhidas pela técnica de bola de neve (snowball), na qual os participantes iniciais de um estudo indicam novos participantes, e assim sucessivamente, até que seja alcançado o ponto de saturação 20 .

Os critérios de inclusão preestabelecidos foram: não ter filhos; utilizar ou conhecer programas públicos de atenção à saúde da mulher; ter idade reprodutiva entre a década de 1950 , marco do advento das políticas públicas nacionais e a década atual, 2010; ser maior de 18 anos. 
Para coleta de dados, foram utilizadas entrevistas realizadas no período de janeiro a março de 2015, de acordo com as etapas propostas pela história oral19: a pré-entrevista, em que o colaborador recebe informações sobre a pesquisa; a entrevista, com gravação das narrativas e registro dos dados; e a pós-entrevista, com devolução das transcrições dela à colaboradora para aprovação. As entrevistas foram encerradas quando se percebeu a saturação dos dados, sem acréscimo de novas questões referentes ao tema estudado. Neste artigo, as participantes estão identificadas com nomes de flores, estado civil e suas idades.

A leitura das narrativas foi realizada utilizando o modelo proposto por Lieblich, TuvalMaschiach e Zilber ${ }^{21}$, que apresentam quatro combinações: conteúdo holístico ou integral, conteúdo categorial, forma holística ou integral, e forma categorial. Optou-se, portanto, por identificar as histórias, fazer a discussão e a análise delas mediante a apreciação do conteúdo holístico/integral e da forma categorial. No modo de conteúdo holístico/integral, a leitura faz considerações de toda a história e foca sobre o seu conteúdo, possibilitando acesso às apreensões e compreensões dos significados-chave em suas vidas e contextos culturais das mulheres entrevistadas. No modo forma categorial, deve-se olhar a forma e os aspectos de sessões separadas, pressupondo que a forma em que as histórias são apresentadas reflete processos de pensamento. Esta análise considerou a percepção das participantes sobre a construção da identidade feminina e maternidade. Após a análise dos dados coletados, fez-se a interpretação buscando a compreensão do tema por meio de um diálogo com os autores que compõem o referencial teórico da pesquisa.

O estudo foi aprovado sob o CAAE 37866014.9.0000.5149, pelo Conselho de Ensino, Pesquisa e Extensão da Universidade Federal de Minas Gerais (Cepe-UFMG), e as colaboradoras concordaram em participar conforme assinatura do Termo de Consentimento Livre e Esclarecido (TCLE).

\section{Resultados e discussões}

\section{Valores em conflito: a maternidade e as mudanças na identidade feminina}

As transformações históricas que afetam a vida das pessoas, alterando concepções, práticas e identidades sexuais, refletem na forma de fazer-se mulher, na possibilidade de viver prazeres e desejos corporais, ou seja, as transformações históricas são promovidas socialmente. Nessa perspectiva, a própria concepção de corpo é engendrada nos processos culturais que produzem e transformam a natureza e a biologia, portanto, é socialmente que os corpos ganham sentido. A inscrição do gênero feminino no corpo leva as marcas de uma cultura; por sua vez, a identidade de gênero e sexual é composta e definida pelas relações sociais. As identidades sociais, portanto, são definidas no contexto cultural e histórico ${ }^{22}$, como se vê na percepção de Violeta:

Porque antes a mulher não tinha liberdade [...] assim, você vê, a mulher hoje ela trabalha em qualquer setor, basta ser habilitada, não é isso? E presta um benefício muito grande, em qualquer... por exemplo na área médica, na área de parapsicologia, psicologia e... ah, tem uma infinidade de... em todas as áreas, a mulher tem prestado serviços. [...] O anticoncepcional, a princípio ele era um horror, o terror, mulher não podia ir à farmácia comprar anticoncepcional, tinha que pedir um amigo... ou pai... nada, o pai, nossa senhora, não podia nem falar com o pai isso, pedia uma pessoa amiga lá para comprar, uma senhora, uma coisa assim, não precisava ser homem não. Mas a mulher não... a mulher solteira não. (Violeta - solteira, 83 anos).

Percebe-se uma diferença de valores das mulheres que vivenciaram o início da pílula anticoncepcional, as mudanças e conquistas provocadas pelo movimento feminista e tudo o que aquele momento representou. Essas mudanças são apontadas em um estudo sobre 
não maternidade e vida profissional, em que "a mulher foi protagonista de mudanças sociais que manifestam uma ruptura em seu modo de ser e agir"16(208). Os resultados apontam que a inserção no mercado de trabalho aparece como uma conquista de independência.

Assim, há um deslocamento da identidade feminina, a mulher passa à construção do feminino baseada no valor do trabalho fora de casa, ao qual confere um valor de constituição identitária que recusa a identidade exclusiva da maternidade. Ou seja, o trabalho feminino remunerado possibilitou a emergência dessa nova posição ${ }^{23}$.

Todavia, o trecho "Mas a mulher não... a mulher solteira não" aponta o surgimento de novos valores em conflito com aqueles já arraigados, em que o ideal feminino estava atrelado à maternidade e à constituição de uma família tradicional, com papéis definidos. Ideal construído cultural, histórica e cotidianamente, influenciado pelas políticas de saúde normatizadoras do corpo feminino e pelos programas assistenciais focados na mulher-mãe, capaz de garantir a configuração familiar 14,11,12.

Gerações diferentes, valores compartilhados. Em um primeiro momento, para Jasmim, a opção era casar e ter filhos:

Eu sou uma jovem senhora considerada adolescente ainda. Sou uma pessoa muito bem relacionada, incluída na sociedade que eu vivo, né... um extenso grupo de amizades, uma mulher comum que já teve seus sonhos de adolescente, alguns desfeitos, e a vida continua... e a gente resolve encarar outros sonhos e outros caminhos. Sou uma pessoa normal, 'uma Cinderela de sapatinho quebrado, lascado' [destaque nosso] [...] [risos]. Sou isto. Algumas escolhas na minha vida não foram bem "escolhas". A vida nos leva a seguir um caminho. A minha ideia... a minha primeira ideia de mulher, de ser humano, de pessoa, era a que todo mundo tem, eu vou casar, ter filho, constituir família e tudo o mais. Esta era a minha primeira ideia de vida. Mas aí os relacionamentos não... não dão certo, os desencontros surgem, as decepções vêm, e depois, aquelas decepções que você acha que são decepções, tornam-se uma coisa comum na sua vida e que você tem que seguir a sua trajetória sem se frustrar muito e continuar levando sua vida. (Jasmim, solteira, 47 anos).

A ideia da maternidade como condição natural da mulher se faz presente, independentemente da idade. Para Jasmim, a primeira ideia era casar-se, ser mãe, como isso não aconteceu, ela se adaptou à situação e se sente feliz, mesmo sem filhos. Ao se definir como uma "Cinderela de sapatinho quebrado", deixa transparecer um certo desapontamento, mas nem por isso deixou de ser Cinderela ou perdeu sua identidade.

Em alguns contextos sociais, ainda se considera como o ambiente natural da mulher a esfera doméstica, a maternidade é direito e dever e o seu exercício anula a identidade da mulher ${ }^{\mathbf{2 4}}$. Na contemporaneidade, mesmo a mulher sendo independente para fazer sua escolha, constata-se que o imaginário coletivo é fortemente marcado pelo discurso da maternidade como condição de feminino:

Eu defino esta como questão de uma... de... é... poder, é... embora ainda numa sociedade extremamente tradicional em relação a algumas questões, de que esta... a maternidade ela não é... a maternidade é uma escolha, nós, diferentemente de outros animais é... é...não temos esse... isto não perpassa por uma questão da natureza humana. O que seria da natureza aí é que a barriga vai crescer, ele vai ser alimentado lá dentro, o corpo vai trabalhar num determinado momento para ele sair, não é isto? Mas o que nós construímos em relação a isto, é de uma construção social e cultural. [...]. Entendo que esse caminho, eu que construo, não há nada que seja da natureza humana, é algo que é da minha construção. [...] todo mundo tem esta expectativa, principalmente para quem casa. Porque mesmo que a sua opção de casar seja sua, eu não quero casar, para a maior parte das pessoas é: nossa, coitada, a pessoa não conseguiu casar: 'ah, ela não conseguiu casar, ah, ela não conseguiu ter filhos'. Não, ninguém quer saber se você optou por não casar, 
as pessoas acham ainda que você não conseguiu [risos]. Não, você lindamente escolheu, não, não quero, não quero este tipo de parceria não, não quero ninguém na minha casa, dividindo comigo. Só que se você faz isto, aí então aceitar que você fez, e ainda não quer filhos? Não, é você dizer não, eu não quero casar, ou então, não, eu não quero ter filhos. [...] eu acho uma sociedade muito organizada para isto, para casamento com filhos. E é muito novo isto na nossa sociedade, assim, as mulheres que não quiseram ter filhos, isto é muito novo, pela escolha é muito novo. (Açucena, casada, 42 anos).

Quando a maternidade se torna uma escolha, e não apenas uma questão da natureza feminina, transforma a identidade da mulher, além de propiciar o rompimento com os valores sociais construídos historicamente. A crítica da Açucena - "ah, ela não conseguiu casar, ah, ela não conseguiu ter filhos" - expressa o preconceito que ela vivencia no seu cotidiano e que ainda existe em relação à mulher que escolhe a não maternidade.

Esse pensamento é corroborado por diversos autores citados por Fidelis e Mosmann"25, em um estudo sobre a maternidade na contemporaneidade. Em resumo, o estudo aponta que a questão da escolha da não maternidade é vista como anormalidade, algo fora dos padrões tradicionais da sociedade, despreparo e como objeto de conflitos para as próprias mulheres. A mulher contemporânea tem outras perspectivas e escolhas não centradas na maternidade, entretanto, assumir essa posição ainda é um desafio no enfrentamento da pressão social e da discriminação. Desse modo, na opinião de Mondardo e Lima, ela constrói novos modelos de funcionamento feminino ${ }^{26}$.

A maternidade possui diferentes faces, diferentes significados em diversos contextos. No entanto, é importante entender como as mulheres subjetivaram esse valor e como fizeram suas escolhas, construindo novas histórias, menos atraídas pelo ideal de mulher-mãe e pelo cotidiano doméstico.

\section{A mulher contemporânea e a não maternidade}

Nos relatos, transparecem interessantes justificativas sobre a escolha da não maternidade, fundamentadas nas histórias de vida de cada mulher, como se pode constatar:

Eu conheci a pessoa com quem eu casei [...] já me veio com uma família formada, tinha separado, três filhos, eu não tinha filhos e nem pensava em ter filhos [...] estamos aí num período de vinte e oito anos casados. [...] tanto aquela experiência tanto que eu vivenciei, de dificuldades, assim, porque querendo ou não querendo, no interior a vida era mais difícil. [...] o que que eu pensava da maternidade, que eu queria mesmo talvez me dedicar a minha carreira, ter minha independência financeira, eu queria assim, ser mais eu. Eu falava assim 'ah meu Deus, se eu separo eu não vou dar conta mesmo de trabalhar e de me dedicar aos filhos... quando eu conheci meu marido... veio me confirmar tudo isso, porque eu não ficava o tempo todo pensando se eu ia ou não ter filhos, nunca pensei... foi assim uma consequência da vida... foi um projeto natural, muito natural, hora nenhuma eu parei debaixo do travesseiro para pensar sobre eu não ter, se eu fiz a escolha certa, ou não fiz, não teve isso... eu não tive, hora nenhuma, isso ai eu te falo assim de coração. (Girassol, casada, 52 anos).

Mesmo sem ter refletido para tomar a decisão de não ter filhos, Girassol apresenta aqui o seu não desejo pela maternidade, o que corrobora estudo ${ }^{16}$ no qual respostas subjetivas mostram que muitas mulheres não se identificam com a maternidade, e encontram outras fontes de satisfação. A maternidade deixa de ser a única conquista, ela tem outras chances, passa a ser reconhecida pelo seu trabalho, faz suas escolhas, torna-se protagonista de sua vida.

Para algumas mulheres, a não maternidade não está atrelada a alguma experiência traumática ou ruim de como foi relatado por outras mulheres, mas fundada no próprio desejo ou visão de mundo: 
Pois é, essa era uma discussão que eu tinha muito com essa professora minha, que as feministas no geral elas não acreditam em instinto materno. [...] eu particularmente eu não acho que seja um instinto materno ou uma coisa que, é... sabe assim... aflore dentro de mim, quando eu vejo um neném... às vezes as pessoas me perguntam: 'mas você vê, quando você passou na ginecologia, na obstetrícia, você não sentiu vontade de ter neném?' Eu não acho que, não é vendo um neném assim que eu tenho vontade de ter filho. [...] Eu não me vejo como uma pessoa que não... não quer ter filhos, mas eu não acho que seja obrigatório uma pessoa também ter filhos, eu não acho que uma mulher que não tem filhos seja uma mulher que não vá ser uma mulher de verdade, assim, toda... não acho. É... eu acho que alguns pontos assim interessantes nesse quesito é porque que as mulheres... por exemplo, assim, eu convivo com muitas mulheres, com alto nível de graduação, pós-graduação, e por que que a mulher não tem filho? (Flor-de-Lis, solteira, 26 anos).

Flor-de-Lis, embora tenha uma visão positiva da maternidade, acredita que nem toda mulher quer ser mãe, que isso não é uma obrigação ou condição de ser mulher. Para ela, essa escolha acontece pelo desejo ou por outros motivos, inclusive profissionais, uma vez que, atualmente, a mulher também está competindo no mercado de trabalho.

As razões circunstanciais apresentadas para justificar a não maternidade, aliadas ao não desejo de ser mãe, permitem uma comparação com a reflexão de que é possível pensar

a possibilidade de uma mulher optar por não ter filhos, uma vez que não existe um instinto inato que a faça desejar a maternidade ou amar incondicionalmente a criança que ela gera26(216).

O que se confirma na narrativa de Gérbera:

Não tive filhos, e aí é uma opção... a minha escoIha tá pautada na minha cabeça hoje, porque eu brinco que amanhã eu não sei o que vai ser, mas até hoje sempre foi uma certeza não querer ter filhos. [...]. Na verdade eu não sei nem dizer se é uma opção, se tem algum momento da minha vida em que eu disse assim: 'bom, vou tomar uma decisão e essa decisão é de não ter filhos'. [...]. Mas eu nunca tive na minha história o contrário, o desejo de tê-los. [...] a minha infância, por exemplo, é... ela não é recheada de histórias de bonecas, de ser mãe, de filhinho, de cuidado, as minhas opções eram sempre os jogos, o esporte, outros desafios, então eu sempre me via mais envolvida com outros tipos de curiosidades, de inquietações, de vontades do que a da maternidade, a da menina, a da boneca, posso contar no dedo eu acho a quantidade de bonecas que eu tive [...] É uma decisão individual mesmo, pessoal, esse desejo não existe, não tá no campo do desejo. Eu acho que o desejo da liberdade, o desejo da individualidade, o desejo do tempo só meu, é... talvez seja egoísmo? [...]. Talvez... não sei o que justifica essa escolha, que não passa por medos, nem biológicos, nem sociais, vamos falar assim, mas que tem a ver com uma decisão particular mesmo? Eu, Fulana, mulher, com quarenta e um anos, não desejo... não desejei, e não desejo ter filhos. Mas gosto do cuidar, gosto das crianças, mas no meu tempo, no tempo da minha escolha, no momento em que eu não estou fazendo outras coisas que eu desejo fazer mais do que ter filhos. (Gérbera, casada, 41 anos).

A emancipação feminina permite à mulher novas possibilidades, garantindo-lhe o direito de decidir sua vida, de ter suas próprias escolhas, de ser livre para pensar sobre o que quer fazer, o que gosta e o que não gosta. Com autonomia sobre o seu corpo e sua vida, muitas assumem a não maternidade com mais tranquilidade, usufruindo a liberdade de fazer suas próprias escolhas.

As possibilidades são muitas: a independência financeira pelo trabalho que possibilita sustentar a escolha, o desejo de liberdade, diminuição da cobrança social e da obrigatoriedade de ser mãe, assim como as justificativas: os medos, as influências sofridas, perdas não elaboradas, identificação maternal, preocupação com a imagem corporal, entre outras coisas, podem definir a escolha pela vida sem filhos ${ }^{16,26}$. 
Não ter filhos por escolha, consciente ou inconsciente, torna-se cada vez mais comum, e no mundo inteiro aumenta a ausência voluntária de filhos. Muitas mulheres se questionam se querem ou não ter filhos, descobrem outras experiências além da maternidade ${ }^{\mathbf{1 3}, 26}$. Essas ideias são corroboradas por estudo ${ }^{18}$ que assegura que as mulheres que escolhem não ser mães se realizam e encontram satisfação em suas experiências e trajetórias de vida. Ademais, se no Brasil a não maternidade é escolha de poucas mulheres, é porque nem todas as escolhas estão disponíveis a todas elas.

Embora a maternidade ainda hoje seja incentivada como marca da identidade feminina, as mulheres têm-se posicionado e feito a sua escolha. Elas conquistaram uma liberdade em seu trajeto histórico, e vão decidir sobre seus desejos e seus corpos.

\section{Outras maternagens}

Entende-se por maternagem a relação que não é condicionada ao aspecto biológico da maternidade, e sim ao afeto e desejo de cuidar ${ }^{27}$.

A maternagem aparece como justificativa para o fato de não terem filhos: o cuidado, a dedicação e o amor aos sobrinhos, de certa forma, preenchem o possível vazio deixado pela não maternidade. $\mathrm{O}$ devotamento foi endereçado a outros, sublimando o desejo de cuidar de seu próprio filho.

Ao afirmar que "os sobrinhos preenchem a não maternidade", Gardênia descreve a maternagem como forma de sublimação:

E como eu tenho muitos sobrinhos, eles preenchiam aquilo. Então isto nunca... Mas eu nunca me incomodei de não ter filhos não. E até muito tempo na minha vida eu não incomodava em não ter filhos não. Meus sobrinhos me preenchiam. [...] só este lado que as pessoas querem mais de você, achando que porque você não tem filho você pode dar [risos] outras obrigações.... Alguém adoeceu, sou eu que vou, todo mundo me cobra isto. Pelo fato... isto aí não é só pelo fato de não ter filho, pelo fato também de não ter marido... então as pessoas me cobram isto muito, que é a parte que eu não gosto, eu posso ir e tudo, mas não quero ser cobrada, e eu sou bastante cobrada neste sentido. É isto aí. (Gardênia, solteira, 68 anos).

Um fator relevante a se considerar é a identificação de uma cobrança pela disponibilidade de quem não tem filhos como uma obrigação de cuidar de outras pessoas, de ter tempo para o outro, e uma responsabilização no papel de cuidadora. O relato também evidencia dois sentimentos: um tom de queixa por ter assumido responsabilidades e um certo grau de satisfação pelo dever cumprido, o que evidencia Magnólia:

Cuido das minhas irmãs, faço tudo. As meninas falam que eu tinha que ser enfermeira. Eu cuido de todo mundo, de minhas irmãs, meus sobrinhos, de quem precisar de mim. [...]. Eu nasci para ser mãe diferente, para cuidar dos meus sobrinhos. Eu cuido dos meus sobrinhos... hoje mesmo eu cuido... de todos se precisar. [...]. Eu não tenho o dom da maternidade de mim, mas ao mesmo tempo eu tenho de cuidar dos meus sobrinhos, entendeu? Cuido, eles conversam comigo... tem problema, eles conversam com a mãe deles? Eles sentam aqui e conversam comigo, de namorada, de problema. (Magnólia, solteira, 52 anos).

Esse cuidado pode ser exercido na dedicação a outras pessoas além dos sobrinhos, com pais, irmãos mais novos, até mesmo com animais. Cuidado este atribuído, culturalmente, ao papel feminino. Ou seja, as mulheres exercem a maternagem, mesmo sem filhos. "As mulheres maternam. Em nossas sociedades, as mulheres não apenas geram filhos"28(118). Com essa afirmativa, pretende-se apresentar o fato que, mesmo não exercendo a maternidade, as mulheres muitas vezes exercem esta função.

Para algumas mulheres, não ter filhos pode não ser tão tranquilo, entretanto, maternar sobrinhos ou irmãos mais novos pode compensar o desconforto causado por essa situação. Um cuidado que tanto pode preencher o espaço de filhos quanto influenciar a escolha pela não maternidade: 
Hoje o meu principal papel é de cuidadora, porque minha mãe mora comigo depois que ficou viúva, há onze anos, quase doze, e meus sobrinhos também, que acabam vindo para cá para estudar e ficam lá em casa. Eu costumo até brincar que eu sou mãe sem ter tido nenhum filho. [...]. Desde criança, quando eu mudei para a cidade, eu por ser a irmã mais velha das mulheres, eu tinha irmãos mais velhos que eu, eu tive que assumir a casa como se eu fosse a dona da casa, então isso de certa forma inviabilizou de viver outras coisas... Depois muito cedo eu comecei a trabalhar, também, isto foi uma coisa importante para mim, e minha vida é isto, meu cotidiano é este. (Dália, solteira, 52 anos).

No relato acerca da maternagem como uma possibilidade de exercer um 'papel feminino' transparece um certo incômodo da Dália pelo fato de não ter filho. Essa constatação nos permite inferir que o processo de cuidar de outro, de certa forma, pode redimi-las de uma culpa, e, ao mesmo tempo, justifica a não maternidade. Importa considerar que a maternagem não é um aspecto exclusivo das práticas femininas, também é uma construção social, e que não exclui os homens de seu exercício.

\section{Considerações finais}

O imaginário social é permeado ainda pela maternidade enquanto condição do feminino. Essa condição que durante muito tempo definiu o papel feminino foi construída cotidianamente, pelos valores partilhados na sociedade pelos discursos do poder. Os saberes médicos foram validados pelo senso comum, criando o mito do instinto materno.

Desconstruir o ideal de mulher-mãe é algo complexo, pois demanda uma conscientização da sociedade e mudança nos valores partilhados. A maternidade possui diferentes significados, de acordo com o momento histórico e com a vivência de cada mulher. Foi também o desejo pela compreensão da experiência da não maternidade que impulsionou a pesquisa apresentada.
No relato das protagonistas desta investigação, ficou evidente que as mudanças sociais impulsionaram a conscientização das mulheres acerca de seu próprio corpo e que, ao apropriar-se dele, elas passaram a tomar decisões de acordo com seus desejos. Nesse contexto, a maternidade já não se apresentou como fator primordial em suas vidas. A mulher, como ser humano, está sujeita a uma multiplicidade de experiências mais ou menos submetidas aos valores sociais de uma determinada época.

As histórias de vida das colaboradoras demonstraram como elas estão distantes da 'condição feminina' estampada nos símbolos e nos mitos inspirados no ciclo biológico que evoca o eterno renascer, o poder de gerar e 'dar à luz' novas vidas. São símbolos que remetem aos estereótipos de um tempo sem medida, ou seja, adaptáveis a qualquer conjuntura histórica. Entretanto, o processo histórico das lutas femininas se contrapôs ao domínio dos mitos e abriu novas possibilidades conquistadas pelas mulheres contemporâneas.

Importa agora considerar as transformações no papel feminino, a autonomia das mulheres para fazer suas próprias escolhas e recusar a maternidade obrigatória, lançando novos ou outros olhares para se dar conta da complexidade que é ser mulher.

\section{Colaboradores}

Machado JSA (0000-0003-0161-2300)* contribuiu para a concepção, o planejamento, a análise e a interpretação dos dados; revisão crítica do conteúdo; e aprovação da versão final do manuscrito. Penna CMM (00000001-5277-2860)*, orientadora da pesquisa, contribuiu para a análise e a interpretação dos dados; revisão crítica do conteúdo; e aprovação da versão final do manuscrito. Caleiro RCL (0000-0002-3734-4494)* contribuiu para a análise e a interpretação dos dados; revisão crítica do conteúdo; e aprovação da versão final do manuscrito.
${ }^{\star}$ Orcid (Open Researcher and Contributor ID). 


\section{Referências}

1. Badinter E. Um amor conquistado: o mito do amor materno. Rio de Janeiro: Nova Fronteira; 1985.

2. Frassão MCGO. Saúde é só para a mulher mãe: as políticas públicas em questão. In: Anais do $9^{\circ} \mathrm{Semi}-$ nário Fazendo Gênero; 2010; Ago 23-26; Florianópolis. Florianópolis: UFSC; 2010. p. 1-9. [acesso em 2016 maio 20]. Disponível em: http://www. fazendogenero.ufsc.br/9/resources/anais/1278287079_ ARQUIVO_SAUDEESOPARAAMULHERMAE.pdf.

3. Vazquez GGH. Maternidade e Feminismo: notas sobre uma relação plural. Rev Trilhas Hist. 2014; 3(6):167181.

4. Vazquez GGH. Sobre os modos de produzir as mães: notas sobre a normatização da maternidade. Rev Mosaico. 2014; 7(1):103-112.

5. Badinter E. O Conflito: a mulher e a mãe. Rio de Janeiro: Record; 2011.

6. Dias MOLS. Quotidiano e poder em São Paulo no século XIX. São Paulo: Brasiliense; 1984.

7. Maia CJ, Jardim AFC. Michel Foucault e a crítica ao sujeito constituinte: diálogos com a teoria feminista. Rev Caminhos Hist. 2008; 13(2):81-90.

8. Costa JF. Ordem médica e norma familiar. Rio de Janeiro: Graal; 1989.

9. Carloto CM, Silvano MA. A família e o foco nas mulheres na política de assistência social. Soc Debate. 2008; 14(2):153-168.

10. Ortega F. Biopolíticas da saúde: reflexões a partir de Michel Foucault, Agnes Heller e Hannah Arendt. Interface comun. saúde educ. 2003; 8(14):9-20.

11. Foucault M. História da sexualidade I: a vontade de saber. 19. ed. Rio de Janeiro: Graal; 2010a.

12. Foucault M. Em defesa da sociedade. São Paulo: Martins Fontes; 2010b.
13. Barbosa PZ, Rocha-Coutinho ML. Ser mulher hoje: a visão de mulheres que não desejam ter filhos. Psicol. soc. (Impr.). 2012; 24(3):577-587.

14. Maffesoli M. O conhecimento comum: introdução à sociologia compreensiva. Porto Alegre: Sulina; 2010.

15. Fiorin PC, Oliveira CT, Dias ACG. Percepções de mulheres sobre a relação entre trabalho e maternidade. Rev. bras. orientac. prof. 2014; 15(1):25-35.

16. Smeha LN, Calvano L. O que completa uma mulher? Um estudo sobre a relação entre não-maternidade e vida profissional. Psicol. Argum. 2009; 27(58):207217.

17. Perrot M. Minha História das Mulheres. São Paulo: Contexto; 2016.

18. Gonçalves E. Solteira, sem filhos: menos que meia pessoa? Mediações. 2017; 22(2):479-509.

19. Meihy JCSB. Guia prático de história oral: para empresas, universidades, comunidades, famílias. São Paulo: Contexto; 2011.

20. Baldin N, Munhoz EMB. Educação ambiental comunitária: uma experiência com a técnica de pesquisa snowball (bola de neve). Rev. Eletrônica Mestr. Educ. Ambient. [internet]. 2011 [acesso em 2016 maio 20]; 27:46-60. Disponível em: https://www.seer.furg.br/ remea/article/view/3193.

21. Lieblich A, Tuval-Mashiach R, Zilber T. Narrative research: reading, analysis and interpretation. Thousand Oaks, CA: Sage; 1998.

22. Louro GL. Pedagogias da sexualidade. In: Louro GL, organizador. O corpo educado: pedagogias da sexualidade. 2. ed. Belo Horizonte: Autêntica; 2001. p. 7-34.

23. Lipovetsky G. A terceira mulher. São Paulo: Companhia das Letras; 2000.

24. Machado AL. A maternidade, o trabalho doméstico e 
a identidade feminina: um estudo particular. Linhas.

2007; 2(1):1-9.

25 Fidelis DQ, Mosmann CP. A não maternidade na contemporaneidade: um estudo com mulheres sem filhos acima dos 45 anos. Aletheia. 2013; (42):122-135.

26. Rios MG, Gomes IC. Casamento contemporâneo: revisão de literatura acerca da opção de não ter filhos. Est Psicol. 2009; 26(2):215-225.
27. Gradvohl SMO, Osis MJD, Makuch MY. Maternidade e Formas de Maternagem desde a Idade Média à Atualidade. Pensando Fam. 2014; 18(1):55-62.

28. Mansur LHB. Sem filhos: a mulher singular no plural. São Paulo: Casa do Psicólogo; 2003.

Recebido em 18/03/2019

Aprovado em 25/10/2019

Conflito de interesses: inexistente

Suporte financeiro: não houve 